\title{
INOVAÇÕES EM ROTINAS: UMA CONCILIAÇÃO POSSÍVEL
}

INNOVATIONS IN ROUTINES: A POSSIBLE CONCILIATION

DOI: http://dx.doi.org/10.21714/raunp.v8i2.1438

Francisco Oliveira Machado

Doutor em Administração, Mestre em Engenharia de Produção. Professor Adjunto da Universidade Federal de Pernambuco. E-mail: francisco.machado@hotmail.com

Envio em: Fevereiro de 2016

Aceite em: Março de 2016

\section{RESUMO}

0 presente trabalho é um ensaio teórico. Ele foi desenvolvido no intuito de se ter uma contraposição teórica entre os temas: Rotinas Organizacionais e Inovação. Como consideração encontrada ao desenvolvimento do artigo, tem-se que a rotina, algo com padrão estável e contínuo, é a base para 0 surgimento de inovações. Para tanto, teorias da (1) Estruturação Social, na qual tem por limites dois reinos, onde as regras e rotinas são inseridas em seu cerne, 0 institucional e 0 das ações; e de (2) Rotinas, com seus aspectos performativos e ostensivos, foram estudas em contemplando alguns de seus modelos. Ao final do trabalho, algumas proposições de estudos são feitas no intuito de servirem de base a trabalhos empíricos futuros.

Palavras-chave: Rotinas Organizacionais. Teoria da Estruturação Social. Inovações.

\section{ABSTRACT}

This paper is a theoretical essay. It was developed under intention to make a contraposition between distinct themes: Organizational Routines and Innovation. As principal consideration founded, we can consider routines, something stable and pattern continuous of action, as like the basis for the emergence of innovations. To this end, theories of (1) Social Structure, between two realms limits, the institutional and of the actions realms, where are inserted the rules and routines; and (2) routines with their both performative and ostensive aspects were studied in contemplating some of their models. At the end of this paper, three theoretical propositions were made to provide a basis for future empirical works.

Keywords: Organizational Routines. Theory of Social Structure. Innovations. 


\section{INTRODUÇÃO}

As organizações podem ser compreendidas como "emaranhado" de rotinas e regras que determinam o rumo de ação comum e comportamento das pessoas (WEICHBRODT; GROTE, 2010). Esse emaranhado unem as pessoas e as coordenam em prol da execução de seus objetivos, de suas metas, determinando os passos do que se deve fazer para estes serem alcançados (BECKER, 2004) e melhorados ao longo de seu próprio executar (FELDMAN, 2000). Objetivos e metas que necessitam de ações para serem materializados. Ações que, com o decorrer do tempo, passam a ser um padrão de interação recorrente adotado pelas pessoas, materializam-se nas rotinas organizacionais (BECKER, 2004; 2005a; 2005b).

As rotinas são a genética da organização (NELSON; WINTER, 1982) e se desenvolvem tendo por base regras (GROTE; WEICHBRODT, 2007) criadas para registrar e codificar, normalmente, em artefatos (PENTLAND; FELDMAN, 2008), o que deve ser feito e evidenciado no comportamento produtivo das pessoas, nas suas rotinas na prática (GROTE; WEICHBRODT, 2007).

Para Feldman (2000) rotinas organizacionais são o padrão repetitivo, que todas e quaisquer organizações possuem e que podem vir a ser modificadas quando há a ativação de um fluxo circular que se inicia com (1) ideias, que são materializadas em (2) planos, com os quais buscam-se (3) ações a fazer, nas quais as (4) saídas são seu resultado esperado, ou não. Esse fluxo foi aprimorado, mais adiante no tempo pela autora, que chegou a desenvolver um circulo da criação de recursos (FELDMAN, 2004), que nos remete a discutir a formação de recursos estratégicos semelhantemente ao tratado pela Teoria da Visão Baseada em Recursos (RBV) (BARNEY, 2002).

Feldman (2004) alega que recursos permitem que pessoas atuem nas organizações em conformidade a esquemas de como proceder em determinadas situações da vida rotineira. Nesse proceder, diante de diversas possibilidades de ações, na relação esquemas de agir e recursos que se têm disponibilizados, como conhecimento, dinheiro e tempo, é que a possibilidade de criar novos recursos é desenvolvida (FELDMAN, 2004). Ou seja, pode-se inferir que as rotinas desenvolvem alternativas à organização para lidar com situações adversas, mudanças ambientais e restrições no agir ante o planejado. Estas alternativas são próprias e imbricadas no percurso histórico de cada organização, como alegou Nelson e Winter (1982). A forma encontrada em cada realidade, inclusive em organizações que possuem unidades distintas, como a obra de 82 ressalta, pode até comparada com o "O", de organização, do arcabouço VRIO da RBV (BARNEY, 2002).

Uma forma de manter o elo entre as partes, na qual cada uma saiba o que fazer e como fazer, ocorre por meio das rotinas e regras (WEICHBRODT; GROTE, 2010). As rotinas são necessárias para a mudança nos procedimentos e ações das pessoas, segundo Feldman (2000) e Feldman e Pentland (2003). Estas duas últimas obras alegam que as rotinas organizacionais são fonte de flexibilidade e mudança, na qual, a rotina, algo estável por essência, é base para que algo novo surja e seja inserido no que já está estabelecido. Quando tal fato ocorre uma nova rotina passa a ser criada.

A rotina, algo estável por natureza, é base ao desenvolvimento e surgimento de mudanças que podem ser consolidadas em inovações. Dessa forma, surgiu a necessidade de se estruturar um arcabouço teórico que tivesse rotinas por base ao desenvolvimento de inovações. Ou seja, o pressuposto de que as rotinas, que uma determinada organização possua, são fontes de mudanças contínuas (FELDMAN, 2000) deve ser base. Com a nova ideia posta em prática, surgem inovações que são comumente mais incrementais do que radicais (FAGERBERG, 2005). Por serem mais incrementais, são denominadas, normalmente, de melhorias (PENG; SCHROEDER; SHAH, 2008).

Assim, buscando entender como estas melhorias ocorrem no processo produtivo, nas ações das pessoas, o presente trabalho tem finalidade a montagem de um arcabouço conceitual sobre os seguintes temas: Rotinas Organizacionais e Teoria da Estruturação Social. Estes dois temas, tendo por norte o surgimento de inovações, servem de base para o surgimento de proposições de estudo a serem contempladas em estudos futuros.

\section{ROTINAS: DEFINIÇÕES E} CONCEITOS NORTEADORES

$\mathrm{O}$ estudo de rotinas não possui um marco que o delimite, porém, um dos primeiros estudos que distinguem rotinas em seu cerne foi o de Nelson e Winter (1982), com a proposta de "uma teoria evolucionária da mudança econômica". Essa teoria é decorrente de modificações da demanda ou de inovações promovidas pelas firmas. Nelson e Winter (1982) alegam que 
as firmas possuem certas regras de decisão e capacidades, porém, elas são modificadas ao longo do tempo para superar problemas que sejam postos à prova.

Para Nelson e Winter (1982), o termo utilizado para definir os padrões de comportamento, que a firma possui regularmente e previsivelmente, é "rotina". O conceito de rotina envolve decisões, sejam estas de cunho operacional, de qual técnica empregar, bem como de nível político superior, de qual estratégia seguir. As rotinas adotadas, quando relacionadas a decisões a tomar, envolvem variáveis externas, de mercado, como internas, como capacidade produtiva. Porém, há tomadas de decisões que não são rotineiras, alegam Nelson e Winter (1982).

Outro autor que se destacou na definição do que vem a ser rotina foi Becker (2004; 2005a; 2005b). Seus estudos apontam a uma evolução do conhecimento acerca do tema. Contudo, o trabalho principal sobre a revisão de literatura acerca do que vem a ser rotinas organizacionais é o de Becker (2004), que buscou elucidar dois questionamentos: (1) o que são e (2) qual efeito as rotinas têm na organização. Em relação ao primeiro questionamento, elencou oito aspectos e sobre o segundo, definiu seis consequências.

As características das rotinas são: (1) Padrão, possuidor de quatro termos que o caracteriza, (i) ação, (ii) atividade, (iii) comportamento e (iv) interação; (2) Recorrência, a principal característica da rotina (BECKER, 2004, p. 646); (3) Natureza coletiva, por demandar múltiplos atores atuando em conjunto ante às regras (GROTE et al., 2009); (4) Esforço Consciente versus Inconsciência, na qual o segundo aspecto é decorrente do cumprimento das pessoas às determinações das rotinas sem pensar sobre; (5) Natureza Processual das Rotinas, que facilita o entendimento das mudanças como um processo; (6) Dependente do contexto, determinante à não replicação de rotina em contextos diferentes; (7) Dependente do Caminho/Trajeto, na qual a rotina se constrói ao longo do tempo, tendo sempre referência ao que aconteceu no passado; e (8) Gatilhos, que podem ser internos, a relação dos atores, e externos, provenientes de eventos, segundo Becker (2004, p. 653-654).

Como efeito do estabelecimento de rotinas em organizações Becker (2004) aponta: (1) Coordenação e controle; (2) Trégua entre os envolvidos; (3) Economia de recursos cognitivos aplicados, na qual o processar de informações das pessoas devem ser canalizados a objetivos selecionados gradativamente; otimizando a capacidade de tomar decisão do agente; (4) Redutora de incerteza; (5) Estabilidade, que pro- move base para todas as decisões internas, inclusive à mudança, que ocorre normalmente de forma incremental, endogenamente inerente à rotina; e (6) Armazena conhecimento, as rotinas o armazenam, por isso podem ser utilizadas como mecanismos heurísticos, desde a confecção de regras e a adoção de certos tipos de artefatos, bem como são nelas onde o acesso a conhecimento tácito é possível de ser feito, segundo Becker (2004).

Como conclusão de seu trabalho, Becker (2004, p. 662) apresenta as rotinas sendo interpretadas como regularidades cognitivas ou comportamentais, bem como, como predisposição a estabelecimento. Em relação às regularidades, rotina pode ser tida como "padrão de interação recorrente". Em relação à predisposição a estabelecimento, rotina passa a ser vista como regras, procedimentos operacionais, que normalmente são corporificadas em artefatos (PENTLAND; FELDMAN, 2008). Nessa linha de raciocínio, Becker (2004, p. 662) conclui o estudo demonstrando quatro efeitos das rotinas nas organizações: (1) elas habilitam coordenação; (2) promovem algum grau de estabilidade no comportamento; (3) economizam recursos cognitivos, que são limitados; e (4) são considerados blocos que constroem as capacidades organizacionais.

Portanto, o mais relevante a este estudo é considerar que rotinas das organizações armazenam conhecimento a respeito de determinada tarefa, são fontes de conhecimento representando soluções para problemas específicos, representam as memórias da organização (BECKER, 2004). Memória que é repassada, ao longo do tempo, pelas pessoas e por entre elas, solidificando seus hábitos e experiências perante um grupo. Como também, neste acessar das memórias organizacionais, que são as rotinas, as pessoas possam ter novas interpretações aos fatos passados, consequentemente, podem criar seu futuro de modo diferente, contribuindo ao desenvolvimento de inovações. Questões similares foram levantadas por Feldman (2000) em seu ciclo, ao se utilizarem de Emirbayer e Mische (1998), no que tange ao papel do agente.

\section{ROTINAS: SEUS ASPECTOS} OSTENSIVOS E PERFORMATIVOS EMBASADOS EM ARTEFATOS

Feldman (2000) caracteriza as rotinas em performativas, o cerne de seu modelo, e em ostensivas. 
Sobre as ostensivas a autora alega que elas devem ser desprovidas de pensamento ativo. No aspecto performativo a agência é inserida. Ao se ter os ensinamentos de Emirbayer e Mische (1998), Feldman e Pentland (2003) alegam que o conceito de agência envolve a habilidade de relembrar o passado, imaginar o futuro e responder diante das circunstâncias presentes. Portanto, rotinas organizacionais são re- sultantes da performance e do entendimento destas pelas pessoas. São ações interdependentes que são compreendidas, não imutáveis objetos estáticos que se assimila. Porém, o modelo de Feldman (2000) consiste em visualizar o fluxo, que inclui pensamentos, sentimentos, ações e experiências das pessoas, em um ciclo de planos, ações, saídas e ideias, como visualizado na figura 1.

FIGURA 1 - MODELO PERFORMATIVO DE APRENDIZAGEM NAS ROTINAS



Fonte: traduzido de Feldman (2000, p. 625).

Este ciclo é suportado pelas ações de restaurar, de esforço e de expansão que mudam as rotinas, quando as saídas influenciam ideias ou valores ao mudar o que as pessoas veem como possibilidade de serem sistematizado em novos planos. Feldman (2000) alega que o processo de inserção em rotinas é um processo de aquisição de conhecimento. Posteriormente, Feldman (2003) chega à conclusão de que a estabilidade nas rotinas organizacionais é resultado do esforço consciente das pessoas em entender as ações que são realizadas. Ou seja, a estabilidade é uma das consequências do entendimento das pessoas, sobre sua própria organização, em como ela opera e guia sua performance dentro das rotinas.

Nesse sentido, Feldman (2003, p. 730) apresenta um modelo de interações entre performance e entendimento, de certo modo, circular. O modelo estabelece a convicção de que as performances relevantes aju- dam pessoas construírem um entendimento de como a organização opera em um determinado momento presente. Este entendimento auxilia na determinação de quais ações fazem sentido para se ter em uma rotina específica. De certo modo resgatando o conceito de agência de Emirbayer e Mische (1998). Sendo assim, as ações das pessoas realizadas em rotinas específicas podem, por sua vez, ter performance relevante que contribui para criar entendimento sobre como a organização opera.

A principal contribuição de Feldman (2003) reside na convicção de que várias possibilidades de se ter performance com o conjunto de rotinas são possíveis. Ou seja, a rotina não é algo estático, ela serve de base ao visualizar, na prática, várias possibilidades de agir. Contudo, as performances não são desconectadas umas das outras, apenas há a que melhor se adéqua pelo entendimento compartilhado das pessoas a um contexto específico. 
FIGURA 2 - MINTERAÇÃO DE PERFORMANCES E ENTENDIMENTOS



Fonte: traduzido de Feldman (2003, p. 730).

No entanto, até o presente momento do presente estudo, diversos conceitos foram expostos sem que definições fossem esclarecidas e delimitadas almejando um direcionamento teórico mais preciso. Termos como regras, rotinas, aspectos ostensivos, aspectos performativos e artefatos que são basilares nos estudos de rotinas, devem ser fortemente categorizados. Pentland e Feldman (2005) associam regras a artefatos e rotinas ao comportamento coletivo. Grote et al. (2009) dividem o conceito de rotina em dois aspectos: (1) rotina em princípio, o conceito que é internalizado e performado em ações repetitivas; e (2) rotina na prática, que surge nas ações e que podem vir a modificar o seu princípio, em circunstâncias específicas. Todavia, o trabalho de Grote et al. (2009) pode ser comparado com os de Feldman (2000; 2003), no sentido de que eles enxergam a ostensividade da rotina como sendo mais próxima da rotina estática em princípio, e a performatividade com a rotina prática, que demanda inevitavelmente por improvisação e flexibilidade.

Regras servem de estamento formal para mostrar a rotina na prática e de compartilhamento pelas pessoas de como as rotinas devem ser compreendidas em princípio, de acordo com Grote et al. (2009). As regras também servem de base ao delimitar do sistema que se quer gerenciar e podem ser classificadas em três tipos, segundo estes autores: (1) de objetivos, onde se quer chegar; (2) de processo, acerca das decisões que devem ser tomadas no curso da ação; e (3) de ação, descrevem as ações concretas a serem realizadas.

Feldman e Pentland (2003) alegam que as rotinas organizacionais são como criadoras de inércia na organização. Elas seriam recurso tanto para mudança quanto para estabilidade, proporcionando à organização a iminência de algum movimento. Nesse sentido, o relacionamento entre os aspectos performativos e ostensivos da rotina cria oportunidades de variar, selecionar e reter novas práticas e padrões de ação dentro de rotinas, possibilitando a ampliação no leque das possíveis saídas (FELDMAN, 2000). Assim, os aspectos ostensivos são inerentes ao saber o quê fazer e os performativos o como vai ser feito, ou como se faz, em um dado momento (FELDMAN; PENTLAND, 2003).

Pentland e Feldman (2005) alegam ser importante estudar as rotinas em associação com a estrutura interna e com a dinâmica organizacional. Assim, eles inserem no debate o conceito de artefato, que pode restringir ou habilitar as rotinas organizacionais em seus aspectos performativos e ostensivos. Artefato é a prescrição ou codificação em diferentes formas, tais quais registros em regras escritas, procedimentos, formas físicas, etc. (PENTLAND; FELDMAN, 2005, p. 796).

Os artefatos são criados para que os gestores possam captar a prática, porém, a realidade se afasta muito da intenção desta apreensão. O saber o que fazer é associado ao conhecimento explícito e o como ao tácito. Dessa forma, quanto mais a pessoa sabe fazer algo, mais ela passa a ter condições de verbalizar o que faz, por isso o uso de artefatos. Contudo, como alertado por Pentland e Feldman (2005, p. 803), é difícil associar o artefato apenas a um aspecto da rotina. Artefatos ligados ao processo de trabalho são mais associados ao aspecto performativo. Já regras e procedimentos operacionais padrão, são mais ligados aos ostensivos. Porém, não é uma associação feita em 
sua plenitude, de forma fechada.

Pentland e Feldman (2005) alegam que a interação dentro das rotinas ocorre de três conjuntos de relacionamentos, que devem ser considerados: (1) Interação Ostensiva-Performativa; (2) Interação Performance-Artefato; e (3) Interação Ostensiva-Artefato. A diferença principal sobre as duas últimas é compreendida pelo fato de que na segunda o artefato surge como controle do comportamento, já na terceira ele surge no intuito de se registrar o que está se fazendo (PENTLAND; FELDMAN, 2005, p. 807). A primeira relação é a base da constituição das rotinas, pois são dois aspectos "recursivos e mutuamente constitutivos", um não existe sem o outro (PENTLAND; FELDMAN, 2005, p. 804).

Três anos após, Pentland e Feldman (2008) come- çam a discutir a desconexão entre objetivos e resultados pelo fato de que muitas vezes é necessário o estabelecimento de padrões de ação e "desenhados" artefatos. O desenho de um novo é relativamente fácil, porém, não resulta, necessariamente, em mudança de padrões de ação (PENTLAND; FELDMAN, 2008, p. 240). Nesse sentido, o artefato deve ser construído para uma rotina que esteja apta a considerá-lo na relação com os aspectos ostensivos e performativos. Em algumas organizações, artefatos são confundidos com os aspectos ostensivos da rotina, o que é um equívoco. Artefatos possuem três dimensões (PENTLAND; FELDMAN, 2008, 242): (1) instrumental, servem de relato dos efeitos das tarefas e objetivos; (2) estética, relacionado à reação sensorial; e (3) simbólica, relacionada ao impacto do artefato.

\section{FIGURA 3 - ROTINAS ORGANIZACIONAIS SÃO SISTEMAS GERADORES}

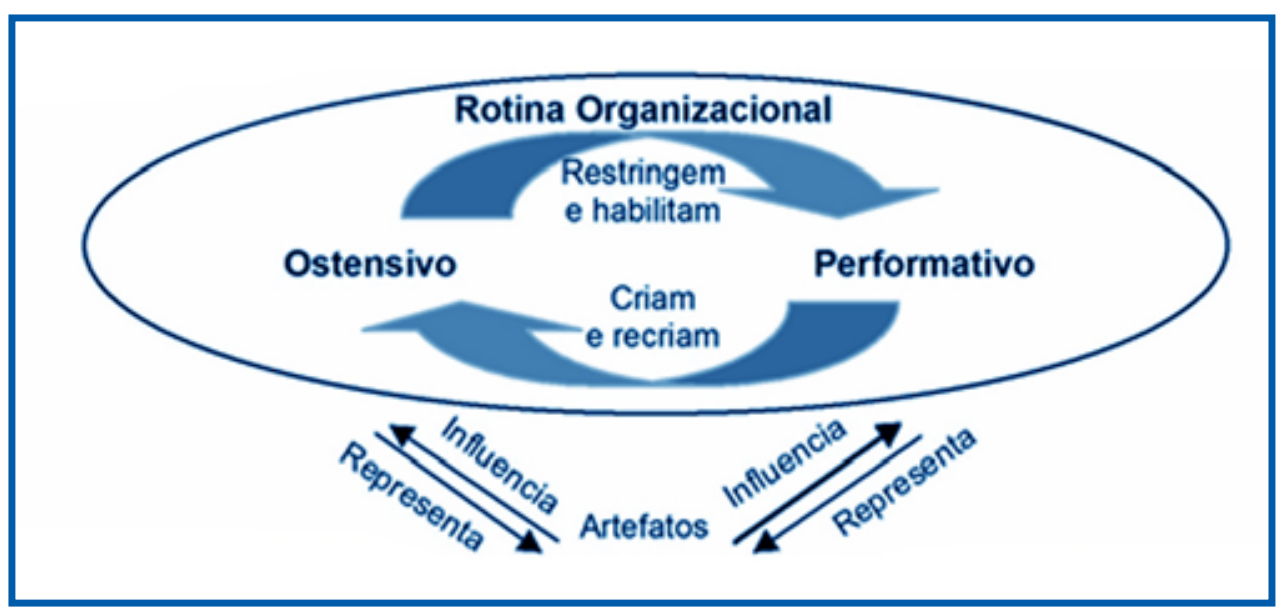

Fonte: traduzido de Pentland e Feldman (2008, p. 241).

Na figura 3, extraída de Pentland e Feldman (2008, p. 241) pode ser visualizada os três conjuntos de relacionamentos mencionados e tratados pelos autores três anos antes (PENTLAND; FELDMAN, 2005). Dessa forma, a rotina organizacional é criada e recriada, restrita e habilitada pelo ciclo presente na interação dos aspectos ostensivo e performativos da rotina. A interação é representada pelos artefatos que influenciam também esta interação. Porém, os artefatos, de certo modo, podem ser considerados recursos da organização, que podem ser: capitais físicos; humanos; e/ou organizacional (BARNEY, 1991). Os recursos podem ser base para o êxito da organização, como também serem restritivos à sua competitividade. Tal analogia remete à possibilidade de ligação teórica quanto ao visualizar da Visão Baseada em Recursos (RBV) e as restrições, especialmente, quando da modelagem do fluxo circular de Feldman (2004) posta na figura 4. 


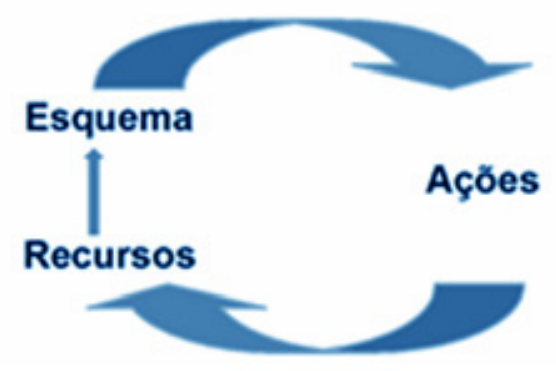

Fonte: adaptado de Feldman (2004, p. 296).

Feldman (2004) defende que as ações tomadas pelas pessoas, delimitadas pelas rotinas organizacionais, criam recursos que habilitam pessoas a desenvolverem esquemas de agir e de criarem mais recursos. Nessa criação, podem surgir inovações em produto, em processo produtivo, de forma radical, incremental, de modo a possibilitar transformações amplas no setor competitivo em que a organização esteja inserida, por exemplo (MOTTA, 2001). Por isso, como já mencionado na introdução deste estudo, acredita-se fortemente que as rotinas são o "O" do arcabouço VRIO da RBV, sendo elas responsáveis por desenvolver altos níveis de competitividades e diferenciação competitiva (BARNEY, 2002).

\section{TEORIA DA ESTRUTURAÇÃO SOCIAL E AS ROTINAS ORGANIZACIONAIS}

Ao se considerar o fato de ser aceito na literatura que a rotina organizacional é definida como padrão repetitivo e reconhecível de ações independentes resultantes de interdependentes ações de vários atores, Feldman e Pentland (2003) inserem na discussão a corrente da teoria sociológica. Assim, os autores alegam que as rotinas são duas partes conectadas. "Uma parte representa a ideia abstrata de rotina (estrutura), enquanto que a outra parte consiste na atual performance da rotina por pessoas específicas, em tempo e lugares específicos (agência)" (FELDMAN; PENTLAND, 2003, p. 95). Na interação entre agência e estrutura há um meio potencial de mudança.

Nessa linha de raciocínio insere-se Giddens (1984), ressaltando-se o fato de que os pressupostos de que sua teoria de estruturação social é fruto da dualidade entre o agente e a instituição. Giddens (1984, p. xvii) alega que a "teoria social" se interessa por entender a natureza da ação humana e do agir, com a qual a interação pode ser concebida e sua relação com instituições, tendo uma conotação das práticas na análise social. A teoria social se interessa por compreender o processo concreto da vida social, portanto, é constituída de esquemas conceituais. Estes esquemas que norteiam a forma como as pessoas podem vir a agir sobre as rotinas e regras, sendo até mesmo confundidos com estas. Regras e rotinas estando postas no centro dos reinos institucional e das ações como apontado por Burns e Scapens (2000).

Para o entendimento da teoria da estruturação, segundo Giddens (1984), faz-se necessário à compreensão de três conceitos: (1) estrutura; (2) sistema; e (3) dualidade na estrutura. A estrutura pode ser compreendida como externa a ação humana, como recurso que restringe esta independentemente da constituição do sujeito. A estrutura é tratada no sentido mais elementar com associação a regras e recursos, nas quais podem ser tratadas como procedimentos metodológicos de interação (GIDDENS, 1984).

Sobre a dualidade da estrutura, Giddens (1984, p. 25) apresenta uma síntese do que vem a ser: (1) estruturas; (2) sistemas; e (3) estruturação. Estruturas são regras e recursos, o conjunto de relação de transformação organizados como propriedade de sistema social. Sistema seria o reproduzir de relação entre atores e coletividade, organizada como prática social regular. Estruturação são as condições de governar a continuidade ou transmutação da estrutura, portanto, a reprodução do sistema social.

Giddens (1984, p. 30-31) distingue três dimensões estruturais do sistema social: (1) significação, na qual o domínio teórico é a teoria da codificação, o controle institucional é por meio dos símbolos e modos 
de discurso; (2) dominação, o domínio é a teoria da autorização e alocação de recursos, que reciprocamente, oriundos da política e economia institucional, como formas de controle; e (3) legitimação, na qual o domínio teórico é da regulamentação normativa e o controle institucional é por meio legal.

Associando a Estruturação Social com a Teoria Institucional busca-se compreender como ocorrem mudanças nas organizações. Sobre as três dimensões o paralelo com os três pilares da abordagem institucional de Scott (1995) pode ser feito, assim tem-se que a dimensão estrutural (1) significação se associa com o pilar cognitivo; (2) dominação com o pilar normativo; e (3) legitimação com o regulador. Nesse sentido é oportuno lembrar que cada um destes pilares possui associação com os mecanismos institucionais de DiMaggio e Powell (1983) respectivamente: mimético, normativo e coercitivo. Também, ressalta-se ser importante este aprofundamento futuro, haja vista o fato de que, recentemente, já se começa a se ter autores como Royer (2015), que insere estas dimensões/ pilares/mecanismos institucionais dentro do que venha a ser a noção de artefatos por Pentland e Feldman (2008).

Portanto, o trabalho de Giddens, particularmente a obra de 1984, consiste em pôr a agência, a reflexão do agente e suas ações com enfoque para se mudar instituições (WHITTINGTON, 1992). Nesse sentido, Whittington (1992) abre a perspectiva para que, se há conhecimento e reflexão, deve-se ter o papel do agente no desenvolvimento da estruturação social. Por isso o maior legado da estruturação social de Giddens é ver o entendimento da sociedade em termos de se ter por lado o reino institucional sendo desenvolvido em paralelo com o das ações das pessoas. Estas pessoas agindo para modificar regras e rotinas ao longo do tempo. Esta mudança sendo incorporada nas instituições (BARLEY; TOLBERT, 1997).

\section{O ARCABOUÇO INSTITUCIONAL NO} MOLDAR DE REGRAS E ROTINAS

A partir da teoria da estruturação social de Giddens (1984), que é dividida em visão de instituições, determinantes ao agir humano, e em estrutura que se forma nas ações das pessoas, começa-se a demandar por ligações sobre as estas duas visões: ações e instituições. Um trabalho começa a apontar para esta ligação é o de Barley e Tolbert (1997). Estes autores desenvolveram um modelo recursivo entre a institucionalização e as ações. O reino institucional contempla um conjunto de regras e tipificações decorrentes de histórias e interações acumuladas que identificam categorias de atores sociais e suas atividades que lhe são próprias (BARLEY; TOLBERT, 1997, p. 95). Barley e Tolbert (1997) ao categorizarem vários níveis de atores sociais que são relevantes, abre a possibilidade de encará-los como indivíduos, grupos, organizações ou até mesmo coletividades amplas.

O reino das ações é o arranjo atual de pessoas, recursos e eventos do fluxo social. Sobre este último, cabe saber como as ações tomadas pelas pessoas passam a afetar o outro reino. O que é recursivo aos dois reinos são os Scripts, que podem ser entendidos como atividades recorrentes e padrão de interação observáveis restritas a uma dada realidade (BARLEY; TOLBERT, 1997, p. 97). Portanto, as instituições compreendem o compartilhar de regras e estas são compartilhadas e performadas nas ações, o que pode ser visualizado no modelo de Barley e Tolbert (1997, p. 100). Os dois reinos são conectados por linhas verticais, que representam as restrições institucionais sobre as ações, e diagonais que são resultado das ações que modificam e/ou mantém o instituído, segundo (BARLEY; TOLBERT, 1997, p. 99).

Posteriormente a este trabalho, Burns e Scapens (2000) estudaram a mudança da gestão contábil em organizações como um processo sobre regras e rotinas que são compartilhadas por dentro da organização e passam a ser diretrizes externas. As mudanças que ocorrem no processo de gestão contábil são fruto das modificações que acontecem nas rotinas organizacionais, suas práticas, que passam a ser potencialmente institucionalizadas (BURNS; SCAPENS, 2000, p. 5).

O trabalho de Burns e Scapens (2000) assemelha-se, em alguns aspectos ao de Barley

e Tolbert (1997), na questão de se ver os dois reinos, o institucional e o das ações, como que em paralelo e algo sendo performado em meio aos dois. No entanto, para o trabalho mais recente, a noção de script passa a ser encarada como uma relação entre regras e rotinas. Estes dois conceitos sendo tratados de forma similar ao conceituado na seção três deste artigo. Para Burns e Scapens (2000, p. 6), regras passam a serem vistas como o modo formal na qual "as coisas devem ser feitas". Regras são necessárias para fornecer coerência nas relações grupais e individuais, portanto, pode-se dizer que elas podem ser presentes em informação contida em manuais, por exemplo, como os de qualidade. A repetição da regra gera o 
comportamento alicerçado em conhecimento tácito de acordo com Burns e Scapens (2000).

Burns e Scapens (2000) tratam as rotinas como sendo representativas do comportamento baseado em regras. Rotinas representam o comportamento do grupo, muitos deles sendo desenvolvidos em cima de algum padrão formal, portanto, elas podem ser definidas como "as coisas que são atualmente feitas" (BURNS; SCAPENS, 2000, p. 6). Nesse sentido, ressalta-se a distinção de hábito e rotina que é feita por estes autores similar a já realizada por Nelson e Winter (1982). Para Burns e Scapens (2000, p. 6), hábito é o comportamento evidenciado e realizado por pessoas. O comportamento que é compartilhado por indivíduos e grupos passa a ser denominado rotina. Ou seja, "regras são estabelecidas e na sua implementação, rotinas irão emergir" (BURNS; SCAPENS, 2000, p. 7).

O modelo de Burns e Scapens (2000) assemelha-se com o de Barley e Tolbert (1997). Essencialmente, a semelhança ocorre na relação agência, ligada a ações humanas e estrutura, à institucionalização que é desprovida de intencionalidade individual, alicerçada no entendimento e estoque de conhecimento coletivo. Devido à proximidade de conceitos, apresenta-se apenas o modelo a seguir para discussões.

\section{FIGURA 5 -O PROCESSO DE INSTITUCIONALIZAÇÃO}

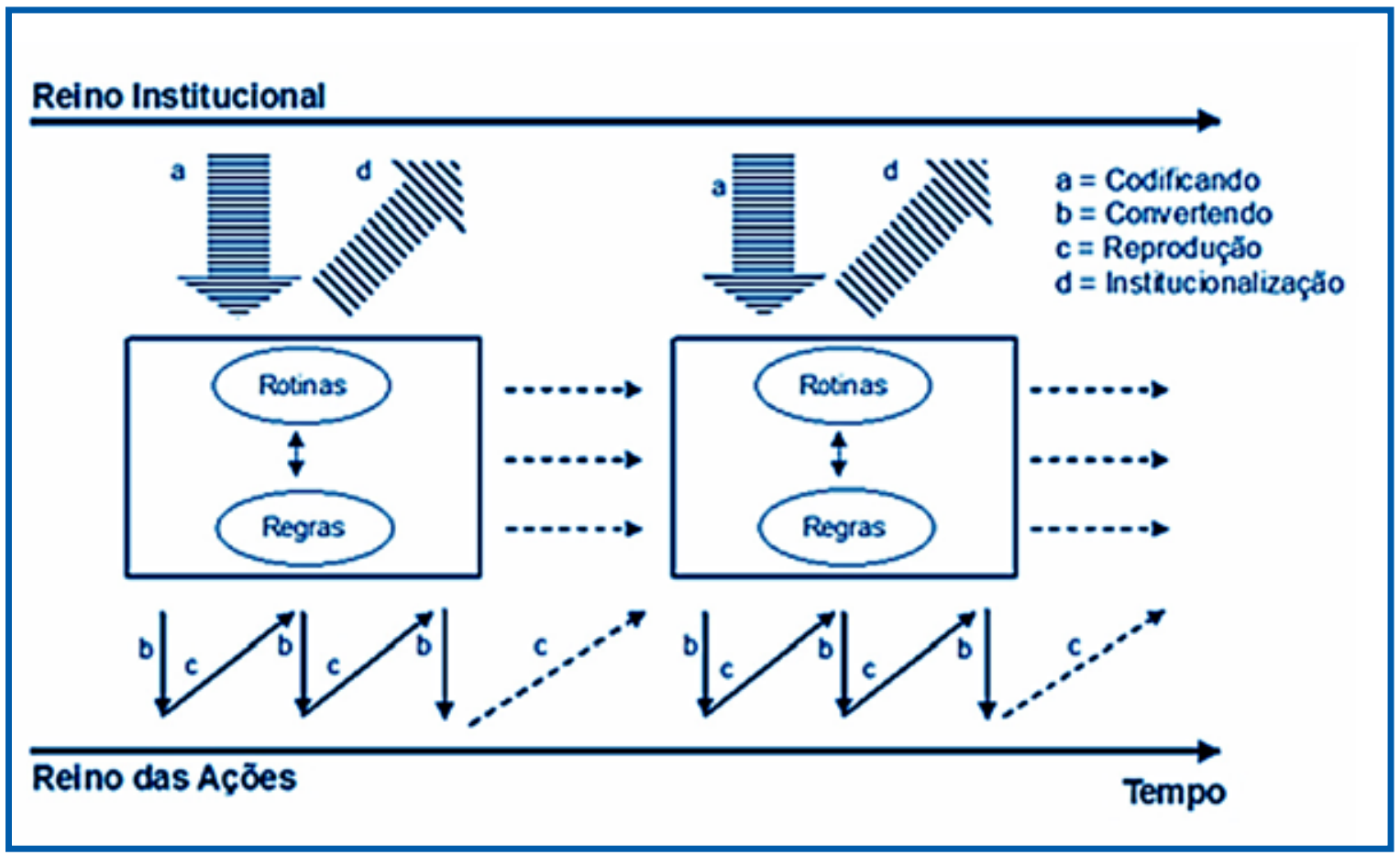

Fonte: adaptado de Burns e Scapens (2000, p. 9).

O primeiro momento idealizado no modelo, representação do que ocorre ao longo do tempo nas rotinas organizacionais, trata-se da codificação dos princípios institucionais em conjuntos de rotinas e regras específicos. Conjunto que, para Barley e Tolbert (1997) são os Scripts. Normalmente, a atuação do "codificar" demanda o processo de socialização e internalização pelos indivíduos de regras e interpretação de comportamentos coletivos. Como se trata de um processo lento e determinante a esta assimilação pelo conjunto de pessoas, a seta representativa parte (e retorna em "d") uma única vez do reino institu- cional de forma mais destacada, mais grossa do que o trabalho de 1997. A diferença ocorre pelo fato de que Burns e Scapens (2000, p. 7) acreditarem que as instituições estarem nos atores, na forma como o "caminho/jeito que as coisas são", não sendo associadas a um determinado contexto em particular, mas sendo aplicado a vários. Por serem mais difíceis de mudar e mais determinantes ao estabelecimento de regras e rotinas, estes "caminhos" são menos frequentes e mais fortes.

O segundo momento é a conversão, que pode não ser consciente completamente, porém a consciência 
se faz importante ao modificar instituições. Converter é referente ao codificar pelos atores do princípio institucional, podendo ser observado elementos tácitos. O terceiro momento do modelo sai do conjunto de regras e rotinas e adentra ao reino das ações, na qual as pessoas revisam ou replicam regras e rotinas passadas por meio da reprodução de ações. Se ocorrem alterações, elas são fruto das ações conjuntas. Por fim, o quarto momento é referente ao desassociar de ações e atores específicos, passando à aquisição de normas que se denomina externalizar e objetivar algo estabelecido socialmente ao reino institucional. Trata-se do momento "d", de institucionalização.

Outras duas diferenças entre os modelos podem ser destacadas. O reino das ações, para Burns e Scapens (2000), possui certa frequência em cima das ações que estão sendo executadas. Isso ocorre devido ao fato de que é necessário ao processo de socialização e internalização dos indivíduos certa repetitividade das ações para que a regra e a rotina passem a serem internalizadas e conhecidas. Após este conhecimento, a reflexão crítica passa a acontecer e a mudança do que está sendo feito passa a ocorrer mais fortemente. Nesse processo, como bem destacaram Burns e Scapens (2000), rotinas emergentes que passam amplamente a serem aceitas na organização se tornam uma forma inquestionável de controle gerencial. Se há controle, pode-se dizer que são institucionalizadas.

Em seguida, como questão modificada por Burns e Scapens (2000) se comparado a Barley e Tolbert (1997) evidencia-se a denominação de que scripts passam a ser denominados de regras e rotinas que surgem e se alteram ao longo do tempo. Sobre o surgimento é pertinente dizer que este é de difícil predição, porém é dependente do caminho, na qual rotinas e instituições existentes moldam a seleção e implementação de novas regras e rotinas (BURNS; SCAPENS, 2000, p. 12).

Porém, como ponto de partida que intitulou o presente trabalho e com base na modelagem apresentada na figura 5, para haver mudança institucional, o entendimento da continuidade e estabilidade se faz presente tal qual um gene, como foi tratado por Nelson e Winter (2005), segundo Burns e Scapens (2000). Estabilidade se faz importante para se compreender mudança, pois elas não são independentes ao que se fazia antes. Estabilidade e mudança são parte de um mesmo processo de acordo com Burns e Scapens (2000), tal qual foi também tratado por Feldman (2000). A dicotomia é percebida e tratada ao contexto da mudança da gestão contábil por Burns e Scapens
(2000) como envolvendo três possibilidades de aprofundamento: (1) mudança formal e informal; (2) mudança evolucionária e revolucionária; e (3) mudança regressiva e progressiva.

A mudança formal normalmente é associada a uma inserção de uma nova regra pensada e planejada. O êxito em sua implementação requer novas possibilidade de pensar das pessoas. Já a informal ocorre em adaptações de cunho mais tácito sobre rotinas que são performadas pelas pessoas. Caso o processo de mudança informal ocorra mais lentamente do que a formalizada, poderá vir a ocorrer ansiedade e resistência das pessoas o que pode comprometer a implementação da "novidade". As mudanças podem acontecer quando da conversão e reprodução que ocorre do e para o reino das ações para com regras e rotinas (BURNS; SCAPENS, 2000).

Mudança revolucionária envolve uma ruptura nas regras, rotinas e instituições que são consideradas pelas pessoas. A evolucionária considera a mudança de modo incremental, normalmente associada à intencionalidade e à formalidade da mudança, na qual as quebras nas rotinas e instituições que são trabalhadas ocorrem de modo mais ameno. Por fim, a dicotomia da mudança regressiva e progressiva como tratada por Burns e Scapens (2000) consiste em que a regressiva é associada ao comportamento que reforçam o cerimonial, que emerge de um sistema de valor que preserva a estrutura de poder atual, portanto, restringem a mudança institucional. Já a mudança progressiva desconsidera o comportamento cerimonial em prol do instrumental. Este é emergente de um sistema de valor que considera a aplicação do melhor conhecimento e tecnologia disponíveis para a solução de problemas.

\section{DISCUSSÃO TEÓRICA: 0}

SURGIMENTO DE INOVAÇÕES EM ROTINAS E SUAS PROPOSIÇÕES

Feita a exposição de duas correntes de estudos: (1) Rotinas Organizacionais, com seus conceitos e definições e seus aspectos ostensivos e performativos; e (2) Teoria da Estruturação Social, contemplada com o arcabouço institucional moldando regras e rotinas, chega-se ao momento de expor algumas proposições de estudo a serem desenvolvidas em trabalhos futuros. As suposições teóricas foram desenvolvidas tendo por base os diversos modelos apresentados nas 
cinco figuras expostas, contudo, ênfase maior foi conferida às figuras 3 e 5.

Proposição 1: $O$ meio ambiente, ao determinar o que deve ser seguido pela organização, força a adaptação da organização à seguir o mesmo, por questão de sobrevivência.

Chega-se a esta consideração proposta, quando, ao se analisar os modelos de Barley e Tolbert (1997) e, sobretudo, o de Burns e Scapens (2000), que tem a seta oriunda do reino institucional mais intensa em suas determinações. Como anteriormente explicado, instituições determinam o "caminho/jeito que as coisas são", e as rotinas internas das organizações, em um primeiro momento, são forçadas à adaptação a esta nova ordem.

No entanto, a adequação a esta determinação institucional pode ocorrer de modo mais alinhado, sem esforço consciente das pessoas (BECKER, 2004), quanto mais consolidada em artefatos (PENTLAND; FELDMAN, 2008), os códigos oriundos do reino institucional advenham. $\mathrm{O}$ artefato, segundo a obra de 2008 surge para, dentre outras, controlar as ações das pessoas. Como a determinação institucional, quando surge, em um primeiro momento, é decorrente do estabelecimento de uma nova ordem, na qual as pessoas dentro da organização devem se alinhar.

Dessa forma, ao se considerar as inovações como esforço consciente das pessoas para alterar incrementalmente ou radicalmente uma ordem estabelecida (MOTTA, 2001; FAGERBERG, 2005), percebe-se que pouco da consciência, de modo amplo por entre os membros da organização é evidenciada. Apenas pode vir a ocorrer a transferências, aos artefatos por parte de quem os confecciona, de novas possibilidades de ação, ou seja, de inovação de fato.

Proposição 2: A influência que o artefato imprime nos aspectos ostensivos e performativos da rotina, apenas permite o melhor desenvolvimento de inovações incrementais à organização.

Esta proposição é decorrente de Pentland e Feldman (2005) alegar que a interação, dentro das rotinas, ocorre de três conjuntos de relacionamentos. Todavia, nas interações Performance-Artefato e Ostensiva-Artefato, é que as inovações possíveis de se obter são incrementais. Julga-se elas serem assim classificadas pelo fato de que o artefato, na "performance-artefato", surge como controle do comportamento, já na "ostensiva-artefato", ele surge no intuito de se registrar o que está se fazendo (PENTLAND; FELDMAN, 2005, p. 807). O controle e o registro não podem ser feitos de forma a comprometer toda uma ordem estabelecida, tem que ser aos poucos, em um processo incremental.

Este raciocínio também encontra respaldo em Feldman (2003), ao concluir que a estabilidade nas rotinas organizacionais é resultado do esforço consciente das pessoas em entender as ações que são realizadas. Ou seja, a estabilidade é uma das consequências do entendimento das pessoas, sobre sua própria organização, em como ela opera e guia sua performance dentro das rotinas. Ou seja, como apresentado na figura 2 , o entendimento de como as organizações operam é o que vai guiar as performances dos indivíduos nas rotinas, portanto, a compreensão das pessoas não pode ser dissociada por completo da realidade vigente. Esse dissociar completo ou intenso pode repercutir em inovações radicais, o que não é o caso. Contudo, ao se voltar para a primeira relação de Pentland e Feldman (2008), da interação ostensiva-performativa, tem que ela é a base da constituição das rotinas, pois são dois aspectos "recursivos e mutuamente constitutivos". Como os próprios autores argumentaram, um não existe sem o outro (PENTLAND; FELDMAN, 2005 , p. 84), e nessa interação é que se acredita poder haver inovações radicais. Sobretudo no restringir e habilitar, no criar e recriar, de forma cíclica, que os autores apresentam e demonstram na figura 3 .

Também, ao se ter os modelos de Barley e Tolbert (1997) e, sobretudo, o de Burns e Scapens (2000), posto na figura 5 , tem-se o processo de conversão e de reprodução sendo executados próximos ao reino das ações. Essa proximidade permite o desenvolvimento de inovações, porém, as de cunho incremental particularmente como se pode contrapor. A reprodução, que ocorre como na interação artefato-ostensivo (PENTLAND; FELDMAN, 2005), é decorrente do registro do que se está fazendo, quando sai do reino das ações e parte-se ao conjunto de regras e rotinas como registro para verificação de desvio ao esperado. A conversão acontece semelhante a interação artefato-performativa, na qual a conversão das regras é decorrente do registro do que se quer fazer e parte-se às ações, ao seu reino. A conversão é decorrente da necessidade de se ter ações tomadas pelas pessoas sendo condensadas e somadas a poucos rumos de ação, a poucas direções possíveis. No converter e reproduzir surgem mudanças de rumo, incrementalmente.

Proposição 3: As inovações radicais surgem quando do esgotar completo das possibilidades de se ter o entendimento de uma rotina ser posto na prática.

Após o esgotar da conversão do artefato ao aspecto ostensivo, e da reprodução do artefato ao aspecto 
performativo das ações rotineiras, surge a necessidade do consolidar de novo conjunto de regras e rotinas, tendo por base o modelo de Burns e Scapens (2000, p. 9). No ir e vir das regras ao reino das ações, no converter e reproduzir, como já mencionado, ocorrem inovações de cunho incremental. As inovações radicais surgem para romper completamente com a lógica processual ou de produto existente (MOTTA, 2001; FAGERBERG, 2005). Elas rompem como o padrão de interação recorrente (BECKER, 2004) vigente. Nessa ruptura, a organização demanda por um novo conjunto de regras e rotinas a cumprir e performar. Dessa forma, supõe-se que as inovações radicais emergem quando da possibilidade de esgotamento da reprodução e conversão do conjunto atual de regras e rotinas e desenvolvimento de novo.

No entanto, antes da passagem, caso a organização desenvolva melhorias significativas neste modo de agir dominante no momento atual, a inovação que se estabelece quando da institucionalização (BURNS; SCAPENS, 2000) é radical. Esta inovação é que será responsável por alterar a ordem vigente no setor (reino institucional), forçando as demais organizações virem a se adequar por um dos três mecanismos isomórficos, institucionais, mencionados, de DiMaggio e Powell (1983): mimético, normativo e coercitivo. Trata-se de inovação radical por vir a modificar radicalmente a forma de atuar de um setor, que terá novos códigos a serem atendidos pelo reino institucional. $\mathrm{O}$ modelo de Burns e Scapens (2000) passa a ser interessante na avaliação destas questões ao longo do tempo.

\section{CONSIDERAÇÕES FINAIS: NA TENTATIVA DE PROPOR UM ENVIESAR TEÓRICO}

Após a apresentação de diversos autores sobre Rotinas Organizacionais, ao final da execução deste ensaio teórico surge a consideração de que inovações apenas acontecem no ambiente interno de or- ganizações. Por organizações, compreende-se a junção de duas ou mais pessoas almejando a conquista de objetivos comuns. Ao serem voltadas as atenções ao ambiente interno organizacional tem-se as organizações compreendidas como "emaranhado" de regras e rotinas, sendo confundidas e tidas como sua genética (NELSON; WINTER, 2005). As rotinas são os elos entre as partes organizacionais (WEICHBRODT; GROTE, 2010) e são elas que permitem à organização lidar com situações adversas, com mudanças ambientais e restrições ante o que foi planejado (FELDMAN, 2004).

Rotinas servem para armazenar conhecimento que são ativados, especialmente, de forma tácita para atuar sobre possíveis desvios de ação, como também, promovem certa estabilidade para que as mudanças ocorram de modo incremental, sem comprometer a ligação entre os indivíduos (BECKER, 2004). Porém, como rotinas remetem ao que está sendo feito na prática, elas geram os recursos organizacionais a serem ativados em conjunto e gerarem vantagem competitiva (BARNEY, 1991). O lidar com os recursos geram esquemas nas pessoas de como agir, antes mesmos delas partirem para as ações. Trata-se do ciclo de recursos de Feldman (2004, p. 296) sendo desenvolvido pelas pessoas.

Contudo, esse ciclo não é fechado. Há o surgimento de "percalços" que modificam as ações, geram ou alteram recursos, modificando os esquemas de agir e, consequentemente, as ações decorrentes. Nesta alteração há inovações sendo desenvolvidas. Nesta forma de pensar e de se contrapor os temas rotinas e inovações foi que se desenvolveu o presente estudo. As suas três principais proposições teóricas decorrentes surgiram do refletir genérico sobre estes dois temas de estudo. Nas mais diversas modelagens apresentadas em trabalhos distintos que tenham rotinas como base, foi possível ligar a visão do estudo de rotinas com o surgimento de inovações. Assim sendo, encerra-se este ciclo teórico alertando a academia ao desenvolvimento e aperfeiçoamento futuro das três proposições feitas. 


\section{REFERÊNCIAS}

BARLEY, Stephen R.; TOLBERT, Pamela S. Institutionalization and Structuration: Studying the links between action and institution. Organization Studies, v. 18, issue 1, 1997, p. 93-117.

BARNEY, J. B. Firm resources and sustained competitive advantage. Journal of Management. v. 17, n. 1, p. 99-120, 1991.

. Gaining and Sustaining Competitive Advantage. 2 ed. New Jersey: Prentice-Hall, 2002.

BECKER, Markus C.. A framework for applying organizational routines in empirical research: linking antecedents, characteristics and performance outcomes of recurrent interaction patterns. Industrial and Corporate Change, v. 14, n. 5, pp. 817-846, September 2005a.

.. Organizational routines: a review of the literature. Industrial and Corporate Change, v. 13, no. 4, p. $643-677,2004$.

. The concept of routines: some clarifications. Cambridge Journal of Economics, vol. 29, n. 2, pp. $249-262,2005 b$.

BURNS, John; SCAPENS, Robert W. Conceptualizing management accounting change: an institutional framework. Management Accounting Research, v. 11, 2000, p. 3-25.

DiMAGGIO, P.; POWELL, W. W. The Iron Cage Revisited: Institutional Isomorphism and Collective Reality in Organizational Fields, American Sociological Review, v. 48, n. 2, p. 147-160, 1983.

EMIRBAYER, Mustafa; MISCHE, Ann. What is Agency? The American Journal of Sociology, v. 103, n. 4, p. 962-1023, jan. 1998.

FAGERBERG, J. Innovation: a guide to the literature. In: FAGERBERG, J.; MOWERY, D. C.; NELSON, R. R. The Oxford Handbook of Innovation. New York: Oxford University Press, 2005, Cap. 1, p. 1-26.

FELDMAN, M. S. A Performative perspective on stability and change in organizational routines. Industrial and Corporate Change. v. 12, n. 4, pp. 727-752, 2003.

Organizational Routines as a Source of Continuous Change. Organization Science. v. 11, n. 6, p. 611-629, Nov-Dec, 2000.

. Resources in Emerging Structures and Processes of Change. Organization Science, v. 15, n. 3, MayJune 2004, pp. 295-309.

; PENTLAND, B. T. Reconceptualizing Organizational Routines as a Source of Flexibility and Change. Administrative Science Quarterly. v. 48, n. 1, PP. 94-118, Mar, 2003.

FAGERBERG, J. Innovation: a guide to the literature. In: FAGERBERG, J.; MOWERY, D. C.; NELSON, R. R. The Oxford Handbook of Innovation. New York: Oxford University Press, 2005, Cap. 1, p. 1-26.

GIDDENS, Anthony. The Constitution of society: outline of the theory of structuration. Cambridge/UK: Polity Press, 1984. 


\section{raUnP}

GROTE, Gudela; WEICHBRODT, Johann C.. Uncertainty Management Through Flexible Routines in a High-Risk Organization. In: 2nd Annual Cambridge Conference on Regulation, Inspection \& Improvement. Cambridge/UK, Sept/2007. Proceeding... p. 1-17.

GROTE, Gudela; WEICHBRODT, Johann C.; GÜNTER, Hannes; ZALA-MEZÖ, Enikö; KÜNZLE, Barbara. Coordination inhight-risk organizations: the need for flexible routines. Cognition, Technology and Work, v. 11, issue 1, Jan. 2009, p. 17-27.

MOTTA, P. A. Transformação Organizacional: a teoria e a prática de inovar. Rio de Janeiro: Qualitymark, 2001.

NELSON, Richard R.; WINTER, Sidney G. An evolutionary theory of economic change. Cambridge, MA: Belknapa Press of Havard Universit Press, 1982.

PENG, David Xiaosong; SCHROEDER, Roger G.; SHAH, Rachna. Linking routines to operations capabilities: A new perspective. Journal of Operations Management. v. 26, p. 730-748, 2008.

PENTLAND, Brian T.; FELDMAN, Martha S.. Designing routines: On the folly of designing artifacts, while hoping for patterns of action. Information and Organization, v. 18, p. 235-250, 2008.

Organizational routines as a unit of analysis. Industrial and Corporate Change, v. 14, n. 5, pp. 793-815, Aug. 2005.

ROYER, Isabelle. Maintenance institutionnelle et routines organisationnelles : Influences réciproques entre les artefacts légaux et les routines. In : Groupe d'étude sur la pratique de la stratégie, HEC-Montréal. Working Paper. 2 décembre 2015.

SCOTT, W. Richard. Institutions and organizations. Thousand Oaks: Sage, 1995 - Capítulos 1, 2, 3 e 4.

WEICHBRODT, Johann; GROTE, Gudela. Rules and Routines in Organizations: a review and extension. In: Fourth International Conference on Organizational Routines. Nice/France, June/2010. Proceeding... p. 1-35, June/2010.

WHITTINGTON, Richard. Putting Giddens Into Action: Social, Systems and Managerial Agency. Journal of Management Studies, v. 29, n. 6, p. 693-712, November 1992. 